\title{
Netnografia da natação e das práticas corporais aquáticas na educação física escolar
}

\author{
Netnography of swimming/aquatic body practices in school physical education \\ Netnografía de la natación y de las prácticas corporales acuáticas en la educación física \\ escolar
}

Murilo Nazario ${ }^{\mathrm{I}}$

\begin{abstract}
Resumo
Esta pesquisa buscou responder à seguinte questão: como as práticas corporais aquáticas e a natação, em específico, enquanto conteúdos de ensino da educação física escolar, são difundidas no ciberespaço das redes sociais? Assume como objetivo discutir e analisar, a partir da netnografia, o lugar das práticas corporais aquáticas/natação no âmbito da educação física escolar. Para tanto, realizou-se uma netnografia nas redes sociais Facebook, Instagram, Twitter, LinkedIn e Youtube. Os resultados sinalizam para um contexto de incipiência no que tange ao processo de ensino aprendizagem envolvendo a natação em âmbito escolar e difundidas no ciberespaço. No entanto, nota-se a difusão do ensino desse conteúdo a partir das rotinas de sequências pedagógicas compostas de conteúdos que priorizam o domínio técnico gestual dos quatro nados clássicos. Há também uma prevalência do ensino desse conteúdo nos cotidianos das escolas particulares, todavia em formato de escolinhas e como propaganda extracurricular.
\end{abstract}

Palavras-chave: Natação; Práticas Corporais Aquáticas; Ciberespaço

\begin{abstract}
This research sought to answer the following question: how are aquatic body practices and swimming, in particular, as educational content in school physical education disseminated in cyberspace on social networks? Its objective is to discuss and analyze, based on netnography, the place of aquatic/swimming body practices in the context of school physical education. To this end, a netnography was carried out on the social networks Facebook.com, Instagram.com, Twitter.com, Linkedin.com and Youtube.com. The results point to an incipient context regarding the teachinglearning process involving swimming aquatic practices in the school environment and disseminated in the cyberspace. However, there is the spread of teaching this subject from the routines of pedagogical sequences composed of contents that prioritize the technical gestural domain of the four classic swims. There is also a prevalence of teaching this content in the daily lives of private schools, however in the format of coaching and as extracurricular advertising.
\end{abstract}

Keywords: Swimming; Aquatic body practices; Cyberspace

\footnotetext{
${ }^{\text {I } U n i v e r s i d a d e ~ V i l a ~ V e l h a ~-~ U V V / E S ~-~ E n d e r e c ̧ o: ~ A v e n i d a ~ C o m i s s a ́ r i o ~ J o s e ́ ~ D a n t a s ~ d e ~ M e l o, ~} 21$ - Boa Vista II, CEP: 29102-920 Vila Velha - ES Brasil, - email: murilo_nazario@ hotmail.com
} 


\section{Resumen}

Esta investigación buscó dar respuesta a la siguiente pregunta: ¿cómo se difunden las prácticas corporales acuáticas y la natación, en particular, como contenido educativo en la educación física escolar en el ciberespacio de las redes sociales? Su objetivo es discutir y analizar, a partir de la netnografía, el lugar de las prácticas corporales acuáticas / natación en el contexto de la educación física escolar. Para eso, se realizó una netnografía en las redes sociales Facebook.com, Instagram.com, Twitter.com, Linkedin.com y Youtube.com. Los resultados apuntan a un contexto incipiente en cuanto al proceso de enseñanza-aprendizaje que involucra la natación en el ámbito escolar y difundido en el ciberespacio. Sin embargo, existe la difusión de la enseñanza de estos contenidos a partir de las rutinas de secuencias pedagógicas compuestas por contenidos que priorizan el dominio gestual técnico de las cuatro clásicas nadadas. También prevalece la enseñanza de este contenido en la vida diaria de las escuelas privadas, pero en el formato de actividades complementarias y como publicidad extraescolar.

Palabras clave: Natación; Prácticas corporales acuáticas; Ciberespacio

\section{Introdução}

Pesquisas sobre natação e práticas corporais aquáticas têm suscitado diferentes discussões e reflexões, com destaque para os aspectos relacionados ao processo de ensino e aprendizagem em âmbito escolar, principalmente em suas ausências (FERNANDES E LOBO DA COSTA, 2006). Carlan e Durks (2018) sinalizam que há diferentes razões para esse cenário, com destaque para as condições de infraestrutura, poucas escolas com piscina, segurança pedagógica do professor, cultura esportivista e ainda a formação no ensino superior direcionada para o ensino instrumental racional voltado para os quatro nados, que mais se assemelha aos espaços de iniciação e performance esportiva, em âmbito não escolar. Esse contexto contribui para as ausências de discussões que envolvem as resoluções desses problemas, colabora para incongruências que envolvem decisões metodológicas, sentidos e finalidades do ensino desse conteúdo e, ainda, influencia nas possibilidades no que tange a sistematização e organização pedagógica ao longo das etapas da educação básica.

Para Fernandes e Lobo da Costa (2006), o ensino da natação deve orientar-se para além da finalidade envolta na aprendizagem dos quatro nados clássicos, crawl, borboleta, peito e costas, embora eles devem constituir-se como um dos conteúdos a serem compartilhados. Para isso, os autores, sugerem uma proposta alicerçada nos conhecimentos da aprendizagem motora, que permita compreender a natação como:

Um conjunto de habilidades motoras que proporcionem o deslocamento autônomo, independente, seguro e prazeroso no meio líquido, sendo a oportunidade de vivenciar experiências corporais aquáticas e de perceber que a água é mais que uma superfície de apoio e uma dimensão, é um espaço para emoções, aprendizados e relacionamentos com o outro, consigo e com a natureza (FERNANDES E LOBO DA COSTA, 2006.p.06).

Catteau e Garoff (1990) consideram que as práticas pedagógicas desenvolvidas ao longo do tempo nos processos de ensino aprendizagem e treinamento que envolvem a natação podem ser inseridas em três correntes: 1) global, 2) analítica e 3) moderna. Na primeira, o processo é marcado por situações de 
aprendizagem, por vezes sem a presença e organização do professor e o desenvolvimento do aluno se dá pela imprevisibilidade das situações oferecidas pelo meio aquático, de modo não sistematizado. $\mathrm{Na}$ segunda, ocorre o oposto, o processo é racionalmente preparado pelo professor e apresentado aos alunos, estipulando métricas de aprendizagem, principalmente a partir de modelos definidos. Na última, a preocupação reside em nadar e não somente em aprender os nados, ao passo que a estratégia busca melhorar os elementos que compõem e estruturam o processo de ensino aprendizagem da natação, ou seja, alunos, professores, ciência e o meio líquido.

Essas questões são reatualizadas com a implantação da Base Nacional Comum Curricular (BNCC), ${ }^{1}$ uma vez que esse documento traz consigo encaminhamentos curriculares de natureza prescritiva sobre a seleção e oferta das práticas corporais, compreendendo-as como unidades temáticas de ensino do componente curricular educação física, dentre as quais está a natação/práticas corporais aquáticas.

Por outro lado, esse vazio epistemológico oportuniza a construção de percursos científicos em diferentes veredas, principalmente com características de ineditismo, dentre elas estão aquelas voltadas para o ambiente virtual. A internet e o ciberespaço se apresentam como cenários profícuos de pesquisa, principalmente por se constituírem como continuuns, ou seja, extensões de/e cotidianos próprios, inclusive para analisar possíveis compartilhamentos que envolvem o processo de ensino aprendizagem das práticas corporais aquáticas/natação apresentando-se como lugares emergentes de difusão e compartilhamento de informações pedagógicas.

A internet constitui-se como lugar que se estende em um movimento de interconexão, não existindo mais a relação real e virtual, mas apenas um lugar. Para Levy (1999, p. 47), “[...] o virtual na ótica filosófica é toda entidade desterritorializada capaz de gerar diversas manifestações concretas em diferentes momentos e locais determinados, sem, contudo, estar ela mesma presa a um lugar ou tempo em particular". No caso das mídias sociais como experiências desse virtual, elas podem ser também compreendidas como interfaces, que possibilitam a interação por textos, sons, imagens, vídeos e mesmo a leitura, que permitem a máxima ligação do mundo ordinário com o mundo virtual (LEVY, 1999).

Nesse sentido, este estudo assume como questão norteadora: como as práticas corporais aquáticas/natação, enquanto conteúdo de ensino da educação física escolar, são difundidas no ciberespaço das redes sociais? Assume como objetivo, discutir e analisar, a partir da netnografia, o lugar das práticas corporais aquáticas/natação no âmbito da educação física escolar.

\footnotetext{
${ }^{1}$ A Base será uma ferramenta curricular que subsidiará os projetos político-pedagógicos das 190 mil escolas brasileiras, das creches às escolas de ensino médio. Assim, serão definidos os conhecimentos essenciais que os estudantes brasileiros possuem como direitos (BRASIL, 2019).
} 


\section{Metodologia}

Nessa perspectiva, optou-se por realizar uma pesquisa estruturada com subsídios da netnografia. Para Kozinets (2014) a etnografia digital, ou online, organiza-se a partir da pesquisa sobre comportamentos, percepções e subjetividades constituídas na relação social em rede. Kozinets (2014) sugere quatro ações práticas que podem recuperar procedimentos básicos de metodologia específicos da transposição da etnografia para a netnografia: Entrée cultural, coleta e análise dos dados, ética de pesquisa e checagem de informações com os membros do grupo.

O entrée cultural é a preparação para o trabalho de campo, etapa na qual o pesquisador identifica aspectos que pretende levantar com a pesquisa e seleciona grupos virtuais em que esses elementos poderiam ser validados e/ou compreendidos. Também, nessa fase, foram criadas as contas de acesso e login nas interfaces das redes sociais analisadas.

Desse modo, realizou-se uma netnografia nas interfaces das redes sociais Facebook, Instagram, Twitter, Linkedin e Youtube, utilizando como fonte as narrativas (textuais, imagéticas ou audiovisuais) veiculadas por atores sociais que publicaram sobre as práticas corporais aquáticas e sobre natação nesses espaços. Sequencialmente, foram inseridos os descritores, \#natacaoescolar \#praticasaquaticas \#natacao, \#natacao acompanhada da \#escola, \#praticascorporaisaquaticas em cada uma das redes sociais do estudo. No entanto, vale salientar que outras "hastags", tais como \#poloaquático, \#nadosincronizadoescola, \#hidroginástica, \#exercíciosaquaticos, \#atividadesaquaticas, com ou sem a palavra "escola" ou “escolar", não foram utilizadas como descritores de busca. Justifica-se a opção pelas \# com práticas corporais aquáticas, de forma geral, e as \# com natação, de maneira específica, devido às ambivalências que, por vezes, associam de maneira geral a relação do ser humano com a água a esses dois termos, principalmente o último.

Os procedimentos de observação, registro e extração dos resultados ocorreu entre julho e dezembro de 2020. Em seguida, mediante as recomendações de Kozinets (2014), dadas as particularidades de análise da pesquisa e o volume de resultados já produzidos, preferimos analisar o material já produzido ou obtidos de modo não intrusivo, denominado "dados arquivais". Desse modo, não definimos recorte temporal para inclusão ou seleção de resultados, mas vale dizer que o Facebook e Youtube são as redes sociais que estão há mais tempo em operação no Brasil, desde 2007. O Twitter iniciou suas atividades em 2009. E o Instagram e LinkedIn, desde 2010. Destaca-se, ainda, que a postagem mais antiga que integra o corpus documental dessa pesquisa é proveniente da \#natacaoescolar, publicada em dezembro de 2016, e trata-se do registro de um festival de natação em uma escola particular. 
Cada uma das plataformas possui uma interface específica de interação e discussão. Com isso, iniciou-se o processo de leitura e captura integral das narrativas produzidas. Para tanto, em cada uma das páginas analisadas, convertíamos o conteúdo textual em Portable Document Format (PDF). Dessa forma, foi produzido um corpus arquival de 51 laudas de pdf para os resultados encontrados no Instagram, 27 páginas para o Youtube, 30 no Facebook, 14 para o Linkedin, e 7 no Twitter. Vale salientar que essa ação somente foi possível devido aos perfis dos usuários com privacidade aberta, ou seja, são visíveis de modo público, elemento que contribui nos cuidados éticos da pesquisa.

Kozinets (2014) considera relevante que o pesquisador faça uso de softwares de análise qualitativa para reconhecimento e organização semântica, como Nvivo, Atlas.Ti e ConsumerBase. Desse modo, utilizou-se o Iramuteq $R$, sendo inserido, na interface do software todo o material coletado, procedimento que produziu uma Nuvem de Palavras e uma Árvore de Similitude composta pelos elementos textuais de maior recorrência nas plataformas pesquisadas.

Essa pesquisa integra o projeto Práticas cotidianas em educação física no âmbito da educação básica, cujo número de aprovação, junto ao comitê de ética, é CAAE: 39629020.5.0000.5064.

\section{Análise e discussão dos resultados}

Os procedimentos de análise se organizaram a partir da produção de nuvem de palavras e árvores de similitude, com base nos elementos textuais de maior recorrência nos dados produzidos a partir dos pdfs das narrativas e participações nas interfaces das redes sociais. Diante disso, produziu-se a seguinte nuvem de palavras:

Figura 1 - Nuvem de palavras a partir da recorrência por vocábulo do Iramuteq $R$

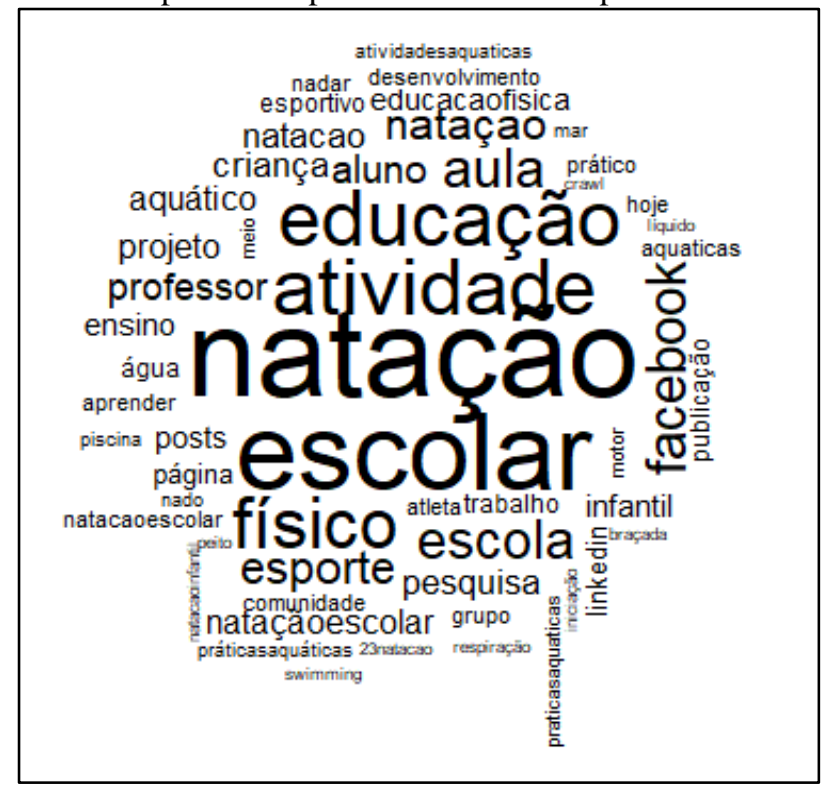

Fonte: elaboração do autor. 
A articulação entre a nuvem de palavras e conteúdo textual integral contribuíram para o desenvolvimento de dois eixos temáticos de análise: cenários de incipiência sobre natação escolar no ciberespaço e práticas pedagógicas em natação escolar compartilhadas no ciberespaço. Em seguida, para ampliar o procedimento de análise, foram extraídos fragmentos textuais completos das interações, comentários e participações nas mídias, com o intuito de situar as palavras produzidas pelo software no contexto das narrativas integrais desenvolvidas pelos participantes.

O primeiro eixo de análise começa a ser evidenciado a partir da necessidade de empregar diferentes descritores, pois sinalizam um dos primeiros indícios do quadro de incipiência de veiculações sobre a natação e as práticas corporais aquáticas em âmbito escolar. Confirma-se, assim, o cenário apresentado pelo campo científico, aspecto que contribui para inferir para a condição de distanciamento da incorporação das práticas corporais aquáticas/natação como conteúdo da educação física escolar e, por conseguinte, compartilhamento nas redes sociais e, consequentemente, na produção científica. Ou seja, a necessidade de diversificação dos termos não apresentou alcance significativo para compreender o alargamento das possibilidades de ações compartilhadas pelos professores com as atividades aquáticas, mas sim para ampliar a amostra de análise. Contribui, ainda, para esse apontamento, a palavra atividade, em destaque, na Figura 1, uma vez que remete à ideia da natação como atividade escolar, e não como conteúdo de ensino.

Do mesmo modo, apresenta-se, de modo ambíguo, e não consensual, o próprio uso das nomenclaturas práticas corporais aquáticas/natação, pois o termo mais abrangente seria o das práticas corporais aquáticas; todavia, devido à tradição de esportivizaçao das diferentes manifestações corporais, natação também estaria associada a outros conteúdos ensinados no meio líquido e compartilhados pelos professores no ciberespaço.

Por outro lado, a negligência no ensino da natação também está associada a diferentes pressupostos que envolvem histórias de vida com a prática, formação inicial, condições de infraestrutura e insegurança docente (CARLAN; DURKS, 2018). Aspectos que colaboram para que haja pouca difusão e compartilhamento desse conteúdo nas redes sociais. Uma vez que se entende, no presente estudo, as mídias como sintaxes, ou seja, as veiculações virtuais atreladas às produções do real, se não há ou se há pouca inserção de tais conteúdos nas aulas de educação física, consequentemente, não há, ou há poucos compartilhamentos nas redes sociais.

Essa condição de incipiência assume novos desdobramentos ao se analisar o contexto ao qual remetem as postagens, uma vez que o uso das hashtags utilizadas acompanhavam o termo escolar, todavia, os compartilhamentos também estavam relacionados aos espaços de escolinhas de iniciação e ensino treinamento propriamente dito fora da escola. Assim, pode-se dizer que, a hashtag escolar é usada apenas 
para alcançar outros sujeitos que se interessam pelo tema escolar, como forma de propaganda virtual para a natação.

No segundo eixo, pode-se averiguar e analisar o modo como são compartilhadas possibilidades de organização didático-pedagógica das aulas sobre práticas corporais aquáticas/natação. Em um primeiro momento buscou-se, com base nas Etnografias clássicas, identificar quem são os sujeitos que compartilham as postagens no Ciberespaço. As combinações desses fatores permitem avançar para além dos elementos que se apresentam pela descrição imediata de uma determinada publicação, tornam-se ferramentas que colaboram no registro e na compreensão das forças invisíveis da subjetividade que permeiam as postagens. Nesse sentido, foi possível encontrar os seguintes perfis responsáveis pela produção das fontes analisadas: 21 instituições de ensino básico particular, 23 professores de educação física escolar, 14 professores de educação física em âmbito extraescolar, 11 academias ou centros de treinamento, 3 clubes ou fundações, 3 familiares, 2 secretarias/prefeitura, 2 eventos, 2 reportagens, 1 político.

Também, inspirados nas etnografias clássicas, buscou-se situar os espaços e tempos apresentados em que as aulas de natação/práticas corporais aquáticas transcorriam. De modo geral, percebe-se a prevalência de compartilhamentos inseridos no âmbito das escolas particulares. Como pode ser melhor observado na figura 2 :

Figura 2 - destaque da natação em aulas de educação física em escolas particulares

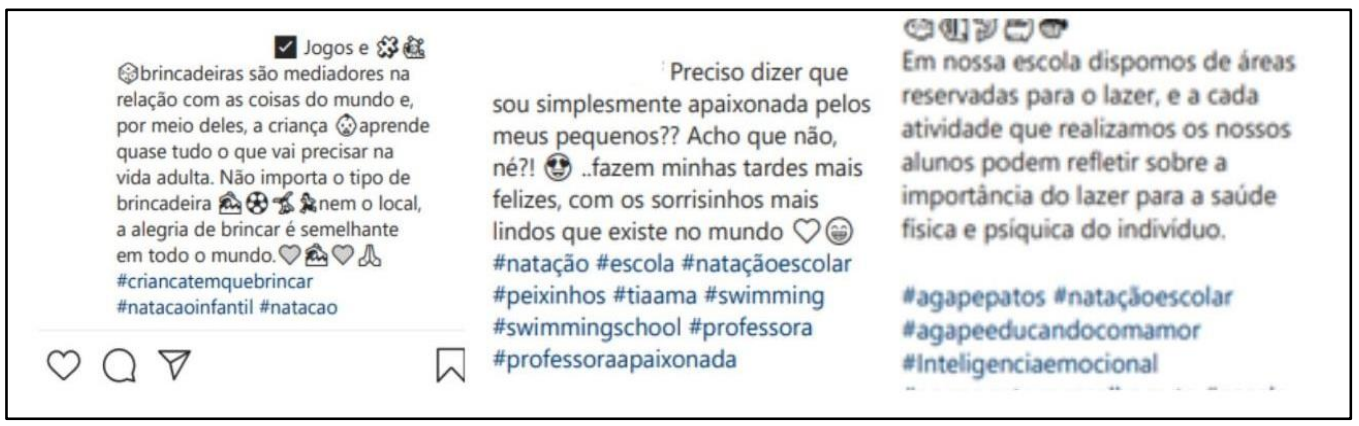

Fonte: extraído do Instagram

Nota-se que as escolas particulares apresentam a natação e as atividades aquáticas como um diferencial, inclusive de propaganda pedagógica de mercado, no que tange aos aspectos concorrenciais com outras escolas. Por outro lado, as postagens também remetem à ideia, principalmente, de ofertar aulas de práticas corporais não como conteúdo do componente curricular educação física, mas sim como espaços contraturnos de iniciação esportiva, no formato de escolinhas.

Aspectos sinalizados por Macedo et al (2007) observaram um número crescente de escolas particulares que ofertavam a natação como atividade extracurricular, inclusive com pagamento de 
mensalidade à parte, e não integrada, como conteúdo da educação física escolar. Identificaram, também, a prevalência da dimensão procedimental, em que se valoriza a aprendizagem técnica dos nados, em detrimento das dimensões atitudinais e conceituais. E, para isso, as turmas eram organizadas por níveis diferentes, com os objetivos da aprendizagem e do aperfeiçoamento dos nados.

Esses elementos colaboram na diluição do sentido e das finalidades de se ensinar natação, prevalecendo a aprendizagem esportividade em detrimento da relação histórica, cultural e crítica que envolvem o ser humano com o meio aquático. Ademais, não se observa a consideração de elementos fundamentais para a aprendizagem, como os indivíduos, ambiente e tarefa, como proposto por Fernandes, Lobo da Costa, (2006).

Nas escolas públicas, por sua vez, foi possível identificar registros de compartilhamento; contudo, com certas particularidades, como na Figura 3:

Figura 3 - aula de práticas aquáticas adaptadas para quadra em escolas públicas

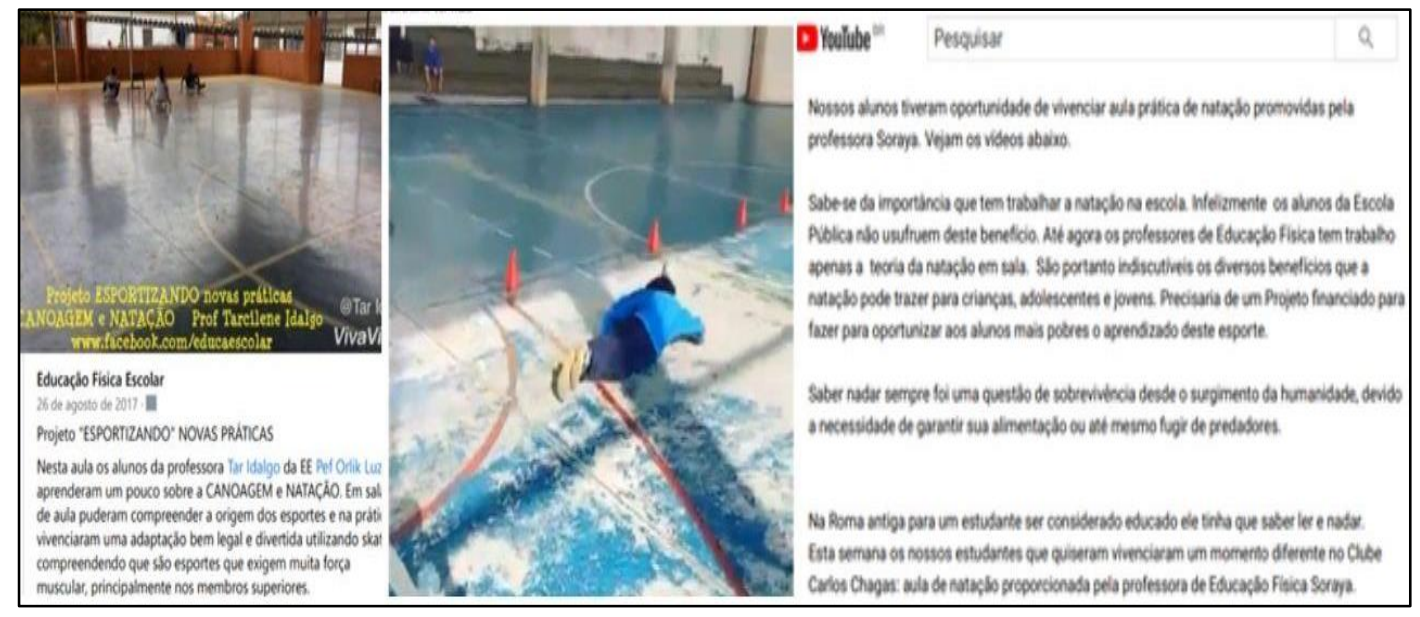

Fonte: extraída de Facebook, Instagram e Youtube

Outro registro significativo, da natação na rede pública envolve ações conjuntas entre universidade e escola, como indica a figura 4. 
Figura 4- Práticas com o conteúdo natação a partir da parceria universidade x escola

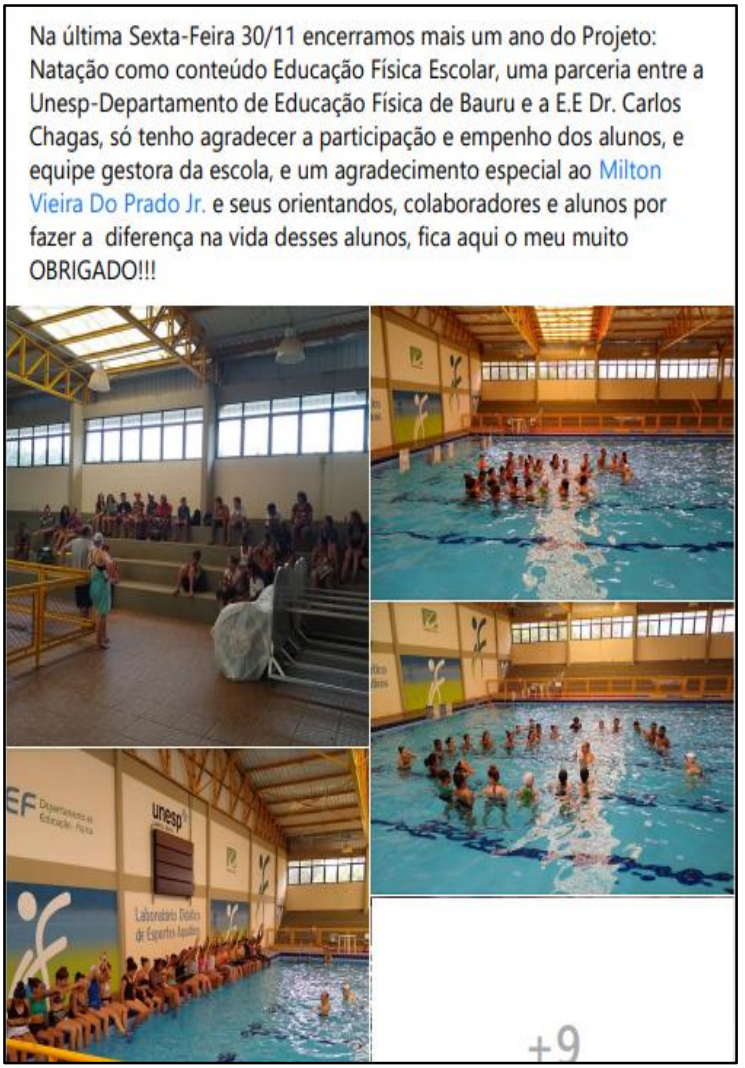

Fonte: extraído do Facebook

Iniciativas dessa natureza poderiam contribuir para o desenvolvimento de ações que amenizassem a ausência do conteúdo natação e práticas aquáticas nas aulas de educação física, bem como as dificuldades didático pedagógicas sinalizadas, uma vez que, boa parcela das universidades, principalmente as públicas, contam com piscina em sua infraestrutura. No entanto, vale considerar que as universidades públicas também têm sofrido impactos de direcionamento de recursos econômicos para manutenção, ampliação ou mesmo construção de infraestrutura que permita o desenvolvimento de ações de ensino, pesquisa e extensão, por meio de uma piscina.

Outro aspecto seria a contribuição na formação inicial e continuada de professores de educação física para ensinar as práticas corporais aquáticas/natação e, ao mesmo tempo, construir possibilidades na ausência de piscinas nas escolas. E, por fim, ações dessa natureza, caracterizando-se como projetos de extensão, poderiam possibilitar a construção de pesquisas e, consequentemente, de publicações que contribuiriam para amenizar as lacunas desse objeto no campo da educação física escolar.

Subsequentemente, ao analisar o modo como as aulas para esse conteúdo eram estruturadas, no que tange as decisões didático metodológicas, foi possível sinalizar a prevalência reducionista das práticas 
aquáticas voltadas para o ensino dos quatro nados da natação, com fortes inclinações ao modelo técnicoinstrumental desportivista, deixando em segundo plano a relação reflexiva ser humano x ambiente (CARLAN; DURKS, 2018; FERNANDES, LOBO DA COSTA, 2006).

Chama a atenção, em uma postagem, a justificativa sobre o lugar da natação em âmbito escolar, a partir do uso dos Parâmetros Curriculares Nacionais (PCNS, 2005), em que, mesmo não apresentando diretamente o conteúdo, ele pode ser interpretado e, consequentemente, inserido no bloco dos esportes, se o ensino priorizar os nados, mas também, no bloco dos jogos e brincadeiras, se o caráter for lúdico, pressuposto confirmado nas postagens que tratavam da recreação aquática. Esses elementos podem ser melhor observados nos dizeres apresentados na figura 5:

Figura 5 - Inserção do conteúdo natação a partir dos PCNS

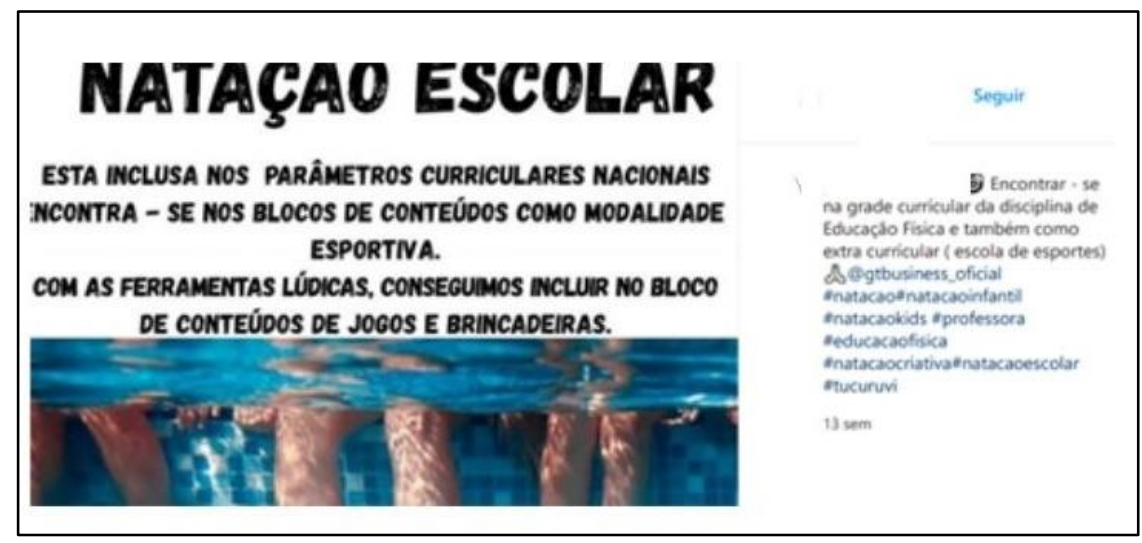

Fonte: extraída do Instagram

Essa condição se repete na publicação que envolve a orientação da escolha e da seleção de conteúdo a partir da BNCC, conforme figura 6:

Figura 6 - Ensino da natação como esporte de marca

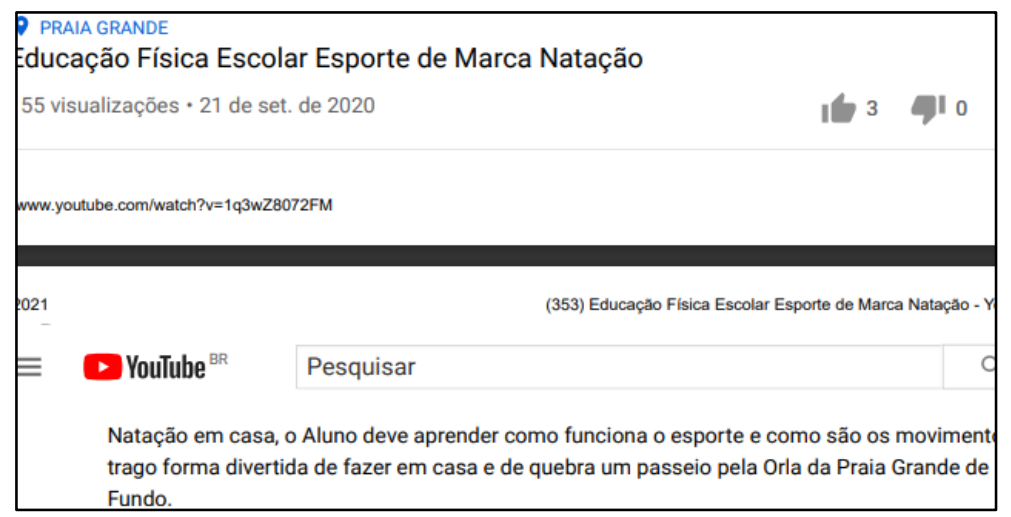

Fonte: extraído do Youtube 
Nas duas imagens, mantêm-se uma visão de natação integrada na ótica esportiva, em específico aos classificados como de marca, caso da figura 7. Essa condição provoca a seguinte reflexão: as práticas corporais aquáticas/natação não poderiam ser exploradas em suas possibilidades epistemológicas como ginásticas, a partir da hidroginástica, ou como nado sincronizado nos esportes técnico combinatórios, das atividades de aventura, como surf, stand up padle, esses últimos ainda podendo ser contextualizados com a questão do mar, pois, nos dizeres, opta-se por um passeio na orla do município de Praia Grande.

Ademais, o próprio documento da BNCC destaca:

\begin{abstract}
Ainda que não tenham sido apresentadas como uma das práticas corporais organizadoras da Educação Física na BNCC, é importante sublinhar a necessidade e a pertinência dos estudantes do País terem a oportunidade de experimentar práticas corporais no meio líquido, dado seu inegável valor para a segurança pessoal e seu potencial de fruição durante o lazer. [...] São, portanto, práticas centradas na ambientação dos estudantes ao meio líquido que permitem aprender, entre outros movimentos básicos, o controle da respiração, a flutuação em equilíbrio, a imersão e os deslocamentos na água (BRASIL, 2019, p. 219).
\end{abstract}

No entanto, essa descrição assume aspectos contraditórios, uma vez que se tal conteúdo se faz relevante, como dito, porque o mesmo não foi inserido como unidade temática. Essa circunstância reafirma os pressupostos envoltos nas dificuldades de inserção e ensino da natação e das práticas corporais aquáticas no âmbito escolar. Por outro lado, é significativo considerar a perspectiva assumida no que tange a compreensão e os sentidos do compartilhamento envolto nessa prática corporal, para além do viés esportista.

Com isso, prevalece, na maioria das postagens analisadas, a representação do ensino da natação no campo esportivo, aspecto que assume maiores contornos quando se identificam as publicações que envolvem campeonatos escolares com competições de natação, conforme figura 7 :

Figura 7 - competição escolar em Goiás

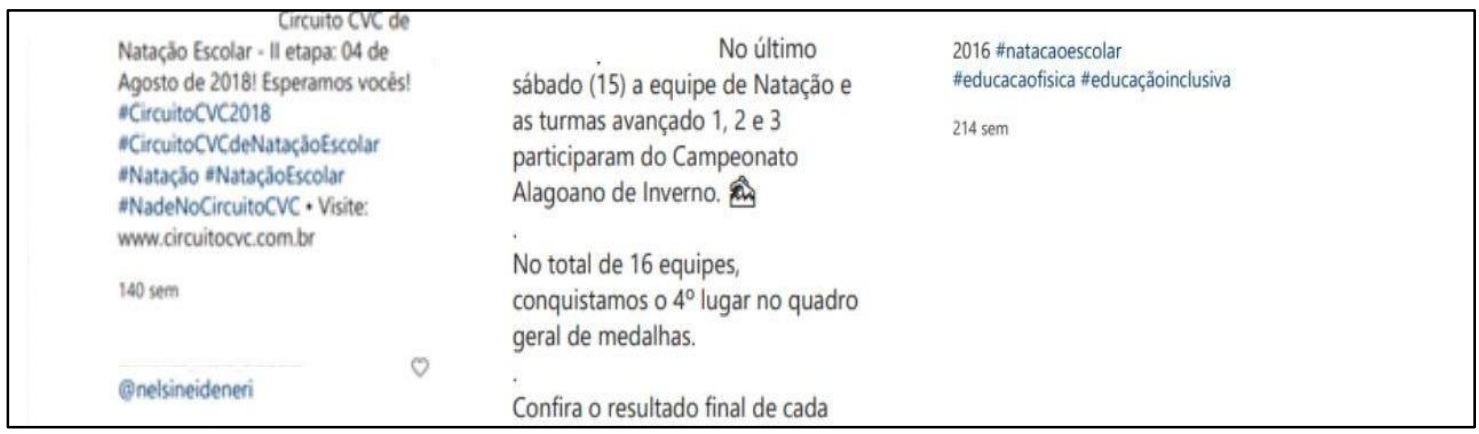

Fonte: extraído do Instagram

Reafirmam-se, assim, as reflexões de Fernandes e Lobo da Costa (2006) sobre a sistematização das aulas de natação na educação física escolar, cuja organização ocorre a partir das rotinas de sequências pedagógicas compostas de conteúdos voltados para os quatro nados. Esse aspecto fica evidente no eixo da 
esquerda, árvore de similitude, Figura 2, que apresenta os grifos braçada, crawl e peito, que, por sua vez, ficam nítidos nas postagens veiculadas no ciberespaço.

Vale salientar que a crítica não se deve à competição em si, mas ao modo como a disputa é inserida no ambiente escolar, esse pressuposto não é exclusivo da natação, cabe também ao tema da cultura corporal, aos esportes, e ao modelo de competição compartilhado no espaço extraescolar. Reverdito et al. (2008) sinalizam dificuldades encontradas para estabelecer as funções educativas em torno do esporte. Isso se deve a diferentes fatores, dentre os quais pode-se destacar a transposição do esporte de competição, sem os devidos tratos pedagógicos necessários, para o contexto escolar. Esse aspecto que contribui para opções de ensino pautadas nas repetições fechadas e modelares, que se assemelham ao praticado com finalidades de formação de atletas. Outro fator preponderante relaciona-se à desconexão entre formato e estrutura do tema com os objetivos, princípios e procedimentos do componente curricular educação física articulados ao Projeto Político Pedagógico (PPP) e com as particularidades de cada contexto e etapa da educação básica.

Gallati e Paes (2006), por sua vez, consideram que, para potencializar os elementos educacionais que permeiam o esporte, é preciso situá-lo como um fenômeno sociocultural, que integra o cotidiano dos alunos de diferentes maneiras, em detrimento à valorização da performance atlética. Com isso, secundarizam o processo de aprendizagem que reside no aprender a nadar e focam no produto dominar mecanicamente os quatro estilos de nado. Como pode ser melhor analisado na figura 8:

Figura 8 - Ensino de técnicas do nado crawl

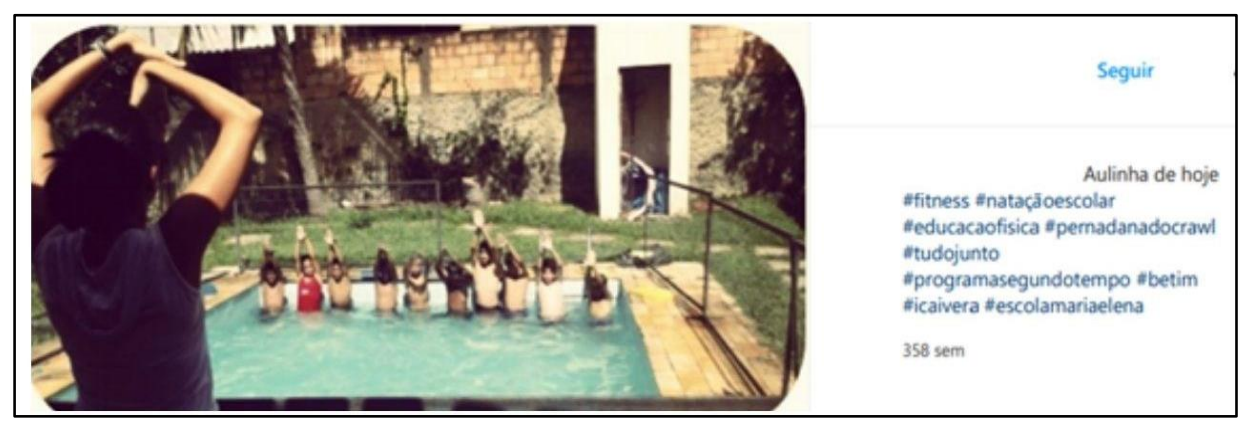

Fonte: extraído do Instagram

Destaca-se em uma das hashtags, da figura 8, que um dos conteúdos que a professora irá utilizar é a pernada do $\mathrm{crawl}$, reafirmando as questões que envolvem a sistematização do ensino da natação centrado na dimensão técnica cuja finalidade são os 4 nados. Catteau e Garoff (1990) situam a discussão sobre o ensino da técnica no campo antropológico, compreendendo-a como resultado de uma produção cultural constituída tradicionalmente por determinado grupo. E, com isso, colaboram para percebê-las como um dos elementos caracterizantes de uma modalidade esportiva, e, com a natação não é diferente, pois apresenta 
gestualidades específicas, conforme os nados e as práticas corporais desenvolvidas no meio líquido. Todavia, sinalizam que a compreensão pedagógica da técnica deve ser aprimorada e não deve se perder as finalidades centrais delas: proporcionar equilíbrio, propulsão com autonomia e sincronia ao aluno. Com isso consideram que toda técnica, por ser imitada inicialmente, no caso da natação, sofreu forte influência das representações e alcances dessa modalidade praticada em âmbito desportivizado, como nas olimpíadas. Com isso, há desdobramentos para uma ideia de melhor ensino a partir da aproximação, ao realizado gestualmente, por atletas.

O que ocorre com a natação é, em suma, o mesmo que decorre sobre a esportização de outras práticas da cultura corporal ${ }^{2}$, que produzem ressonâncias para o amálgama da educação física escolar (BRACHT, 2003). O esporte, como conteúdo escolar, tem sido amplamente discutido na literatura científica, com destaque para as críticas de sua recorrência e, por vezes, pela associação com a monoculturização das aulas de educação física, mas o questionamento a ser feito refere-se ao processo configuracional que possibilita, a essa prática, manter-se como recorrente e representativa nos projetos de escolarização.

Dessa forma, o campo científico precisa ampliar as possibilidades de leitura sobre esse objeto para além das críticas de sua presença. Deve-se deslocar o olhar epistemológico para os motivos de sua presença, permanência e aparente consolidação representativa no cotidiano das aulas de educação física. Ademais, não será pela crítica ao esporte que outras práticas corporais ocuparão um lugar de destaque entre os saberes/fazeres desse componente curricular.

Com isso, perde-se a oportunidade de ampliar o sentido de lugar sociocultural do qual as práticas corporais fazem parte explorando as potencialidades, por exemplo, do interacionismo simbólico envolto nessas manifestações (GRUPO DE TRABALHO PEDAGÓGICO UFPe - UFSM, 1991), inclusive naquelas realizadas no ambiente aquático.

Com isso, os alunos, em suas corporeidades, podem compreender que a aula de educação física e os conteúdos por ela apresentados integram uma realidade social. Dessa forma, existe uma relação interativa e integrativa entre o sujeito e o ambiente, inclusive o aquático, cujas nuances são históricas e críticas. Desse modo, aprender os 4 nados de maneira esportivizada e instrumentalizada, não é suficiente, é preciso, ainda, situar e analisar as desigualdades, por exemplo, de acesso às piscinas, por variáveis econômicas e sociais. A educação deve alicerçar-se em pressupostos de heterogeneidade, buscando como finalidade a homogeneidade, no que tange a elevação dos níveis culturais das massas, contribuindo assim para

${ }^{2}$ A cultura corporal para Soares et al. (1992, 2012, p. 38), 34 é entendida como “[...] o acervo das formas de representação do mundo que o homem tem produzido no transcurso da história, exteriorizadas pela expressão corporal: jogos, danças, lutas, exercícios ginásticos, esporte, malabarismo, contorcionismo, mímica [...]”. 
desnaturalizar, por exemplo, o fato de que escolas públicas não têm piscina. Essa ação se torna necessária, uma vez que a educação como mediação da prática social não sai da realidade para produzir e ampliar a reflexão sobre as formas de transformação social.

Nesse sentido, o lugar histórico e crítico das Práticas Corporais aquáticas significa, também, sinalizar, para a compreensão de certas estruturas, uma delas, se relaciona ao conteúdo-destinatário, ou seja, a seleção das diversas manifestações corporais aquáticas, deve considerar os contextos socioculturais em que os alunos estão inseridos, que por sua vez incide sobre o método a ser escolhido, pelo professor, e os procedimentos de ensino. Ou seja, repensar os sentidos dessas práticas na dimensão histórica e social passa por ressignificar as decisões didáticas suscitadas no compartilhamento desse conteúdo de ensino. Em suma, o professor deve orientar-se os caminhos didático-pedagógicos, valorizando a busca de uma superação da síncrese à síntese pela análise e configuração estrutural dialética. Resgatando a premissa básica da educação como mediadora da prática social, ou seja, constituindo a uma dada sociedade tempo histórico, cuja finalidade é promover o máximo das capacidades afetivo cognitivas no educando para que ele contribua na transformação social do que está a sua volta (MARSIGLIA, MARTINS E LAVOURA,2019).

Do mesmo modo, rios e mares passam a constituir-se como partes inerentes da formação e produção cultural de determinado grupo social. Nesse sentido, uma piscina pode parecer distante no campo representativo e do sentido para os alunos, mas uma cachoeira, um lago ou o próprio mar podem não ser. Nessa perspectiva, as postagens também sinalizam a ausência de práticas pedagógicas que explorem os meios líquidos naturais pertencentes às diferentes localidades, como mar, cachoeiras, rios e lagos. Para Dias e Alves Júnior (2007), as representações dos espaços podem ser mediadas a partir das práticas corporais. Para tanto, situam a relação do processo de urbanização em sua expansão e a tentativa do controle e domesticação racional do natural, principalmente por sua interface de imprevisibilidade caótica. Uma vez que o homem moderno, por maior que seja o ímpeto aventureiro dos espaços da natureza, prime também por conforto e seguridade, agindo e controlando os riscos inerentes às atividades ao ar livre. E isso significa, também, esporitivizar as práticas corporais no ambiente da aventura.

Esses pressupostos que contribuem para compreender certas ausências nos resultados para outros conteúdos que envolvem o ambiente aquático, como o surfe, stand up paddle, canoagem e outros que podem ser discutidas e situados em termos epistemológicos e terminológicos como práticas corporais de aventura ou esportes de aventura, não constituindo-se objeto deste estudo. Como indica a figura 9. 
Figura 9 - Diversificação de ensino das práticas corporais aquáticas a partir do Polo Aquático

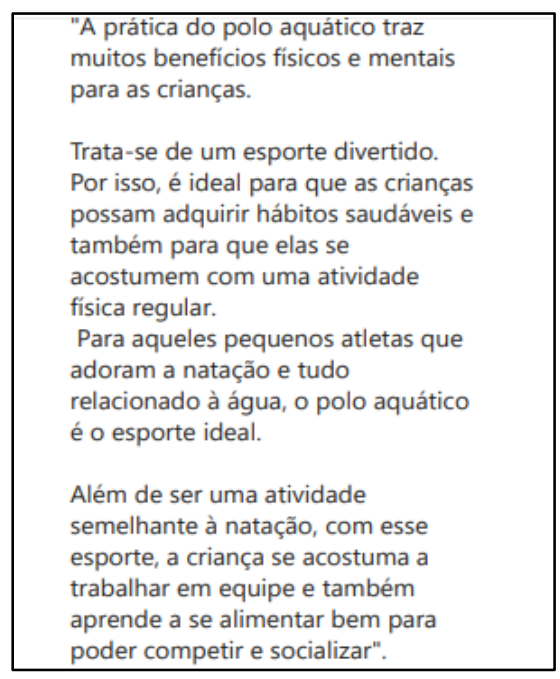

Fonte: extraída do Instagram

Assim, evidenciaram-se apenas duas postagens que remetiam a outras possibilidades que envolvem a tematização e o ensino das práticas corporais aquáticas e da relação do ser humano no meio líquido, no caso do polo aquático, figura 9. Com isso, conteúdos como nado sincronizado, hidroginástica, práticas corporais com prancha em ambiente aquático e salvamento, para citar algumas, não foram compartilhadas como possibilidades de ensino. Diversificações sinalizadas por Fernandes, Lobo da Costa, (2006) e Souza e Silva (2013).

\section{Considerações finais}

As práticas corporais aquáticas e a natação são compartilhadas e difundidas no ciberespaço, de forma ambígua, no que tange a perspectiva e inserção no contexto escolar. Uma vez que, mesmo com direcionamento das hashtags para descritores com o termo "escolar ou escola", predominaram ações didático-pedagógicas empreendidas nos espaços voltados à iniciação esportiva, em ambiente extraescolar. Nas poucas difusões próprias do contexto escolar, prevalecem aquelas voltadas para as escolas particulares, cujo destaque também necessita de certas ponderações, as principais delas referem-se ao lugar desses conteúdos, em que se sobressai a natureza de escolinhas esportivas e não como partes do currículo das aulas do componente curricular educação física. No que tange a rede pública, averíguam-se ações isoladas, organizadas de forma adaptada na quadra ou em sala de aula, ou seja, sem o componente do meio líquido. Isso é resultante do que aponta a literatura científica, falta de infraestrutura, formação dos professores e a tradição da educação física escolar na escolha e seleção dos conteúdos. 
Sendo assim, observa-se que a negligência ou secundarização do ensino das práticas corporais aquáticas no ambiente escolar, apresentado na literatura científica, ganha novos elementos a partir deste estudo, uma vez que as redes sociais e o ciberespaço apresentam-se como sintaxes espaciais, as quais indicam um processo configurativo estabelecido por conexões e relações sociais, expressas por trocas constantes, migrações, deslocamentos e trânsitos de um espaço ou de um lugar para outro. Não obstante, com a elaboração e implementação da BNCC, poder-se-ia construir e ampliar as discussões e reflexões sobre o lugar das práticas corporais, em suas dimensões culturais, sociais e históricas, inclusive aquelas relacionadas ao meio aquático, para além das perspectivas racionais e instrumentais provenientes de uma cultura esportivizante. No entanto, pouco se explora nesse documento, de natureza normativa, essas possibilidades no que tange a natação e as práticas corporais aquáticas.

Nesse sentido, sinaliza-se, para o desenvolvimento de estudos que se insiram no cotidiano das aulas de educação física escolar, em âmbito particular e público, que possam ampliar os motivos das ausências, fragilidades e dos sentidos e significados que envolvem o lugar da natação e das práticas corporais aquáticas no contexto escolarizado da educação básica.

\section{Referências}

BRACHT, V. Educação Física \& Ciência: cenas de um casamento (in)feliz. 2. ed. Ijuí, RS: Unijuí, 2003. BRASIL. Secretaria de Educação Fundamental. Parâmetros Curriculares Nacionais. Educação Física, 1o e 2o ciclos, v.7, Brasília: MEC, 1997.

BRASIL. Ministério da Educação. Base nacional comum curricular. Terceira Versão. Brasília: MEC, 2019.

CARLAN, P.; DÜRKS, D. B. O conteúdo "atividades aquáticas" na educação física escolar: limites e perspectivas. Revista Kinesis, Santa Maria v.36, n.3, p. 2-14, set-dez. 2018.

CATtEAU, R. e GAROFF, G. O ensino da natação. 3 ed. São Paulo: Manole, 1990.

FERNANDES, J. R. P.; LOBO DA COSTA, P. H. Pedagogia da natação: um mergulho para além dos quatro estilos. Revista Brasileira de Educação Física e Esportes. São Paulo, jan./ mar. 2006, v. 20, n 1 , pp. 5-14.

GRUPO DE TRABALHO PEDAGÓGICO UFP/UFSM. Visão Didática da Educação Física: análise críticas e exemplos práticos de aula. Rio de Janeiro: ao livro técnico, 1991.

GALATTI, L.R., PAES, R.R. Fundamentos da Pedagogia do Esporte no Cenário Escolar. Revista Movimento e Percepção, Espírito Santo do Pinhal Vol. 6, No 9, p.16-25, jul.-dez.,2006.

KOZINETS, R. V. Netnografia: realizando pesquisa etnográfica online. Porto Alegre: Penso, 2014. 
LEVY, P. Cibercultura. São Paulo: Ed. 34, 1999.

MACEDO, N. P. et al. Natação: o cenário no ciclo 1 do ensino fundamental nas escolas particulares. Revista Mackenzie de Educação Física e Esporte,v. 6, n. 1, 2007.

MARSIGLIA, A. C. G., MARTINS, L. M.; LAVOURA, T. N. Rumo à outra didática histórico-crítica: superando imediatismos, logicismos formais e outros reducionismos do método dialético. Revista HISTEDBR On-Line, 19, e019003, 2019.

REVERDITO, Riller Silva et al. Competições escolares: reflexão e ação em pedagogia do esporte para fazer a diferença na escola. Pensar a prática, v. 11, n. 1, p. 37-45, 2008.

SOUZA, R., T. A. e SILVA, M S. Atividades Aquáticas diferenciadas nas aulas de Educação Física In: Os desafios da escola pública paranaense na perspectiva do professor PDE artigos. Volume 1.. Cadernos PDE. Paraná. Governo do Estado. Secretaria de Educação, 2013.

SOARES, C. et al. Metodologia do ensino da educação física. São Paulo: Cortez, 1992.

SOARES, C. et al. Metodologia do ensino da educação física. São Paulo: Cortez, 2012.

\section{Como citar este artigo}

NAZARIO, M. Netnografia da natação e das práticas corporais aquáticas na educação física escolar. Revista Kinesis, Santa Maria, v. 39, p.01-17, 2021.

* Este estudo não contou com apoio financeiro de nenhuma natureza para sua realização. 